\begin{tabular}{|l|l|l||}
\hline \multicolumn{2}{|c|}{ PublisherInfo } \\
\hline \hline PublisherName & $:$ & BioMed Central \\
\hline \hline PublisherLocation & $:$ & London \\
\hline \hline PublisherImprintName & $:$ & BioMed Central \\
\hline \hline
\end{tabular}

\title{
Ward interventions prior to ICU admission
}

\begin{tabular}{|l|l|l||}
\hline \multicolumn{2}{|c|}{ ArticleInfo } \\
\hline \hline ArticleID & $:$ & 4135 \\
\hline \hline ArticleDOI & $:$ & $10.1186 /$ ccf-1999-762 \\
\hline \hline ArticleCitationID & $:$ & 762 \\
\hline \hline ArticleSequenceNumber & $:$ & 72 \\
\hline \hline ArticleCategory & $:$ & Paper Report \\
\hline ArticleFirstPage & $:$ & 1 \\
\hline \hline ArticleLastPage & $:$ & 4 \\
\hline \hline & & RegistrationDate : 1999-6-23 \\
\hline ArticleHistory & $:$ & OnlineDate \\
\hline \hline ArticleCopyright & $:$ & Current Science Ltd1999-6-23 \\
\hline \hline ArticleGrants & $:$ & \\
\hline \hline ArticleContext & $:$ & 130541111 \\
\hline \hline
\end{tabular}




\section{Keywords}

APACHE II, cardiopulmonar, hospital, intensive care, mortality, outcome prediction, resuscitation, severity of illness index

\section{Comments}

This paper gives more evidence to support the need for an increasedprovision of HDU/ICU beds in the UK health service. Seriously unwellpatients are being managed on the hospital wards and this may be aconsequence of the difficulties in attaining an ICU bed. Identification ofthose patients at risk, via education of non critical care staff in recognisingsignificant deteriorating physiological variables, is obviously important,but will fail to improve outcome if there is no HDU/ICU place to care forthese sick patients once identified.

\section{Introduction}

The authors have previously shown that patients admitted tothe intensive care unit (ICU) from the ward have the highest mortality. Other studies have shownthat physiological derangements often precede cardiac arrests occurringinside hospital. Consequently it should be possible to identify, at an earlystage, those ward patients who have become seriously ill and requirecritical care, and so improve outcome.

\section{Aims}

To identify physiological derangements and interventions occurringprior to admission of ward patients to the ICU.

\section{Methods}


All patients admitted to the ICU from a ward during a 13 monthperiod (1995/1996) were followed up prospectively. Patients admitted to thehospital for less than $24 \mathrm{~h}$ or who had undergone surgery within the 24 hprior to ICU admission were excluded. Physiological variables were assignedAPACHE II points and scores were recorded for three time periods prior to ICUadmission: 0-6 h, 6-12 h, and 12-24 h. Procedures or interventions priorto ICU admission were recorded, and included administration of continuous positive airway pressure (CPAP), oxygensaturation monitoring and the need for cardiopulmonary rescuscitation (CPR).

\section{Results}

Of the 923 admissions to the ICU over the 13 month period, 79 admissions fulfilled all criteria in 76 patients (some patients were admitted twice). Although the majority of admissions occurred in daylight hours they were spread evenly over the week days and weekends. Forty-seven percent of patients had serious chronic health points as defined by APACHE II, and the average APACHE II score prior to ICU admission was 19 . Cardiopulmonary resuscitation preceded $34 \%$ of admissions and the overall hospital mortality was $58 \%$, although there was no difference in mortality between those who required and those who did not require $\mathrm{CPR}$.

Routine observations were available in $81-89 \%$ of cases, basic haematology and biochemistry results in $91 \%$ of cases, and blood gases in $51 \%$ of patients in the preceding $24 \mathrm{~h}$ period to ICU admission. 80\% of patients had abnormal heart rate, respiratory rate and oxygenation values as defined by APACHE II. However, only respiratory rate showed a statistically significant rise in APACHE II points over the three time periods.

Seventy-five percent of patients received oxygen within $6 \mathrm{~h}$ of ICU entry and the number receiving CPAP doubled over the three time periods, although numbers were small (6.3-12.7\%). The use of pulse oximetry also approximately doubled over this time period (36-61\%) and worryingly $62.5 \%$ of patients had recordings $<90 \%$ within $6 \mathrm{~h}$ of admission to the ICU.

\section{Discussion}

In this study ward patients admitted to the ICU were seriouslyill with a consequent high hospital mortality. Results may have been worseif patients with treatable pathology were included but who died on the wardsand never made it to the ICU. Of all the APACHE II variables, an increasing respiratory rate was the bestprognostic indicator that ICU admission was required. Ward medical staffwere obviously aware that patients were unwell on the wards as reflected bythe increasing number of interventions, procedures and additional monitoringreceived by these patients over the three time periods. Despite this however, onethird of patients required CPR prior to ICU admission and perhaps theseriousness of their deterioration was not fully realised. 
Seriously ill patients require early assessment by specialists in intensivecare medicine, so that initiation of appropriate therapy can prevent acatastrophic deterioration. Abnormalities in certain routinely measuredphysiological variables may help the inexperienced in deciding when help isrequired.

\section{References}

1. Goldhill DR, White SA, Sumner A: Physiological values and procedures in the $24 \mathrm{~h}$ before ICU admission from the ward. Anaesthesia. 1999, 54: 529-534. 